\title{
Determinants and Outcomes of Satisfaction With Healthcare Provider Communication Among Cancer Survivors
}

\author{
Ashish Rai, PhD; Xuesong Han, PhD; Zhiyuan Zheng, PhD; K. Robin Yabroff, PhD; \\ and Ahmedin Jemal, $\mathrm{PhD}$
}

\begin{abstract}
Background: Despite the surge of interest in improving provider communication, empirical research is sparse on the determinants and outcomes of cancer survivors' satisfaction with healthcare provider communication. Methods: Longitudinal Medical Expenditure Panel Survey data spanning 2008 through 2014 was used to identify 4,588 respondents who were ever diagnosed with cancer. A composite score was generated by combining 5 measures of satisfaction. We used multivariate logistic regressions and 2-part models to examine the associations between satisfaction ratings and outcomes, including general, mental, and physical health; office visits; and total healthcare, drug, and out-of-pocket expenditures. Results: The study sample comprised 2,257 nonelderly (age 18-64 years) and 2,331 elderly (age $\geq 65$ years) respondents. Among both age groups, higher satisfaction was associated with fewer comorbidities, fewer year 1 office visits, and absence of year 1 emergency department visits. Membership of higher satisfaction tertile in year 1 was associated with better year 2 mental health (tertile 1 [T1]: predictive margin [PM], 27.1\%; tertile 2 [T2]: PM, 35.5\%; $P=.013$; tertile 3 [T3]: PM, 37.0\%; $P=.005)$ and general health (T1 [ref]: PM, 30.3\%; T3: PM, 38.9\%; P=.007) among the elderly. Greater satisfaction was associated with fewer year 2 office visits (T1 [ref]: PM, 7.42 visits; T3: PM, 6.26 visits; $P=.038$ ) among the nonelderly; and lower year 2 healthcare expenditures (T1 [ref]: PM, \$34,071; T3: PM, $\$ 26,995 ; P=.049)$ among the elderly. Conclusions: We identified potential differences in cancer survivors' needs and expectations of provider communication based on comorbidities and baseline service use. These results emphasize the need for individualized communication strategies for patients with cancer and survivors shaped by their distinct requirements. Our findings of better health, lower service use, and lower expenditures among more satisfied cancer survivors suggest that interventions to improve provider communication could lead to a more efficient use of healthcare resources.
\end{abstract}

Measurement of value in healthcare is key to the movement from volume- to value-based delivery models. In its 2001 report, "Crossing the Quality Chasm: A New Health System for the 21st Century," the Institute of Medicine recognized patient satisfaction as an important measure of value in healthcare. ${ }^{1}$ This report prompted extensive efforts to incorporate patients' experience of care into pay-for-performance initiatives. A decade later, the Patient Protection and Affordable Care Act

\footnotetext{
Surveillance and Health Services Research Program, Department of Intramural Research, American Cancer Society, Atlanta, Georgia.

Submitted July 26, 2017; accepted for publication April 11, 2018.

The authors have disclosed that they have no financial interests, arrangements, affiliations, or commercial interests with the manufacturers of any products discussed in this article or their competitors.
}

J Natl Compr Canc Netw 2018;16(8):975-984
doi: 10.6004/jnccn.2018.7034

$J$ Natl Compr Canc Netw 2018;16(8):975-984
doi: 10.6004/jnccn.2018.7034

(ACA) mandated the adjustment of Medicare payment rates in response to value-based performance scores-a substantive portion of which is measured using patients' assessment of communication with healthcare providers. ${ }^{2}$ The Patient-Centered Outcomes Research Institute (PCORI) established by the ACA also recognizes "communication and dissemination research" as one of its 5 priorities under which studies of patients' values and preferences in communication are encouraged. ${ }^{3,4}$

Author contributions: Study design: All authors. Data analysis: Rai, Han, Zheng. Data interpretation: All authors. Manuscript preparation: All authors.

Correspondence: Ashish Rai, PhD, Surveillance and Health Services Research Program, Department of Intramural Research, American Cancer Society, 30 Speen Street, Framingham, MA 01701.

Email: Ashish.Rai@cancer.org 
Healthcare provider communication is especially germane to cancer care. The anxiety that accompanies cancer diagnosis and receipt of complex information about treatments, costs, and prognosis ${ }^{5-7}$ may render patients more sensitive to what they perceive as particularly good care or communication. Effective communication between healthcare providers, patients, and families is vital at each point along the cancer care continuum, and especially so at the end of treatment. During this transition, fears about cancer recurrence and uncertainty of long-term survival come to the fore. ${ }^{8}$ Numerous questions also arise about next steps in care, including whom to consult, what tests to undergo, and how to manage late and lasting effects of cancer or its treatment. ${ }^{9}$ Addressing survivors' emotional needs, effective communication, and information sharing are essential to patientcentered survivorship care planning. ${ }^{9}$

In a 2007 monograph published by the NCI, Epstein and Street ${ }^{10}$ introduced a framework for patient-centered communication in cancer, organized around 6 functions: fostering healing relationships, exchanging information, responding to emotions, managing uncertainty, making decisions, and enabling patient self-management. The framework conceptualized the role of a trusting patientclinician relationship in optimal delivery of cancer survivorship care that would lead to better continuity of care, adherence to treatment plans, reduced suffering, and reduced morbidity and mortality rates. ${ }^{10}$ Subsequent research led to the development of several survey measures for assessing patient-centered aspects of provider communication in cancer care. ${ }^{11-13}$ However, there is limited empirical research on survivor-level determinants of satisfaction with provider communication and ensuing outcomes, including general, physical, and mental health; service utilization; and costs.

The present study is an extension of an earlier inquiry into the determinants and outcomes of patient satisfaction with provider communication in the general population. ${ }^{14} \mathrm{We}$ analyzed nationally representative longitudinal data to identify factors associated with cancer survivors' satisfaction with healthcare provider communication and examined the associations between different levels of satisfaction and short-term outcomes, including health status, healthcare utilization, and expenditures.

\section{Methods}

\section{Data Source and Study Population}

The data for the study were obtained from the Medical Expenditure Panel Survey (MEPS) household component spanning 2008 through 2014 (panels 13-19). The MEPS is a large, nationally representative survey of health status, healthcare utilization, experiences with care, and expenditures for the US noninstitutionalized civilian population. ${ }^{15}$ Each panel consists of 5 rounds of surveys conducted over approximately 2 years.

The study cohort was identified using the NCI's Office of Cancer Survivorship definition of cancer survivorship, which states "an individual is considered a cancer survivor from the time of diagnosis through the balance of his or her life." ${ }^{16}$ As such, the study cohort included newly diagnosed cancer survivors, long-term cancer survivors, individuals receiving cancer treatment, and those who had completed treatment. Our study cohort is composed of adults aged $\geq 18$ years who were ever diagnosed with cancer (nonmelanoma skin cancer excluded), had $\geq 1$ physician or clinic visit 1 year prior to the first survey encounter, and had no missing data on all satisfaction measures in the first year of the panel.

\section{Satisfaction Measures}

The healthcare provider communication component of the Consumer Assessment of Healthcare Providers and Systems (CAHPS) included with the MEPS asks how often over the past 12 months the respondents' physicians or other health providers accomplished the following: (1) listened carefully, (2) explained things in a way that was easy to understand, (3) showed respect for what the respondent had to say, and (4) spent enough time with the respondent. Response options covered a 4-point scale ranging from "never" to "always." Additionally, the MEPS includes a measure of the respondents' global rating of healthcare received in the past year, ranging from 0 ("worst possible") to 10 ("best possible"). This global satisfaction rating has been shown to be highly correlated with satisfaction with provider communication. ${ }^{17}$ We generated a composite satisfaction score by using the standard approach of combining the $z$ scores (difference between the raw score and the sample mean of a measure divided by the standard deviation of the measure) of the 4 CAHPS measures and the global rating from year $1 .^{18}$ 
Provider Communication in Cancer

\section{Survivor Outcomes}

We evaluated 3 categories of outcomes from year 2: health status, healthcare utilization, and healthcare expenditures. Mental and physical health status was measured using the Mental and Physical Component Summary scores derived from the 12-item Short Form Health Survey version 2 (SF-12v2). ${ }^{19}$ Additionally, the respondents' health on the day of the interview (rated as excellent, very good, good, fair, or poor) was included as a measure of their general health status. Healthcare utilization was measured in terms of total number of emergency department (ED) visits, inpatient admissions, and office-based visits over the past year. Healthcare expenditures were measured as total healthcare expenditure, expenditures on prescription drugs, and out-of-pocket expenditures over the past year.

\section{Determinants}

Respondents' age, sex, race/ethnicity (non-Hispanic white or others), marital status (currently married or others), education (less than high school, high school, or college), poverty level (family income $<100 \%-124 \%, 125 \%-399 \%$, or $\geq 400 \%$ of federal poverty line), and smoking status were identified from panel-year 1 responses (Table 1). Access to healthcare was ascertained using health insurance status (any private, Medicare and/or Medicaid, or uninsured in age group 18-64 years; Medicare only, Medicare and private, or Medicare and other public in age group $\geq 65$ years) and whether the respondents had a usual source of healthcare. The total number of comorbidities $(0,1$, or $\geq 2$ in age group 18-64 years; $0,1,2,3$, or $\geq 4$ in age group $\geq 65$ years) from a list of 8 self-reported ailments (arthritis, asthma, cerebrovascular disease, coronary artery disease, diabetes mellitus, emphysema, hypertension, and myocardial infarction) was used to approximate baseline health status. Additional indicators of health status and proclivity to using healthcare included year 1 Physical and Mental Component Summary scores, self-rated general health, office visits, ED visits, hospitalizations, total healthcare expenditures, drug expenditures, and out-of-pocket spending. Receipt of cancer-related treatment within 2 years of the survey was identified through prescriptions for antineoplastic agents in the MEPS Prescribed Medicines file or through receipt of chemotherapy, radiation therapy, or surgery related to cancer in the Outpatient Visits,
Office-Based Medical Provider Visits, and Hospital Inpatient Stays files. ${ }^{20}$

\section{Statistical Analyses}

Descriptive statistics were stratified by age group (18-64 years and $\geq 65$ years). Analyses were conducted to (1) identify the year 1 demographic and health-related attributes associated with year 1 satisfaction with provider communication, and (2) examine adjusted health outcomes and resource use in year 2 associated with year 1 satisfaction with provider communication.

Using multivariable logistic regression, we examined the associations between respondent characteristics (year 1 sociodemographic features, insurance status, usual source of care, comorbidity count, smoking status, active treatment status, tertile of office visits, any ED visits, and any inpatient care) and membership of the highest satisfaction tertile. This categorization of the dependent variable was based on distributions of the components of the composite score and motivated by the existing literature in this field. ${ }^{21-26}$

Leveraging the panel design of MEPS, we examined the association between satisfaction measures in year 1 and outcomes in year 2 . Year 2 indicators for excellent/very good general health, highest tertile of mental health, and highest tertile of physical health were modeled using logistic regressions. We used 2-part models to account for the abundance of zero outcomes and skewed distributions of nonzero outcomes in healthcare utilization and expenditures. In the first part, we modeled the probability of an outcome being non-zero using logistic regression. In the second part, conditional on a positive outcome, the value of the outcome was fitted using appropriate regression models_-Poisson regressions for healthcare use and gamma regressions with $\log$ link functions for expenditures. All regressions were controlled for the covariates listed earlier and stratified by age.

Adjusted percentages of membership of a group, number of visits, and expenditures are presented as predictive margins (PMs), which standardize the outcome of each group to the covariate distribution of the population. ${ }^{27}$ All statistical tests were 2 -sided and conducted at $5 \%$ level of significance using Stata/IC 14 (StataCorp LLC). We incorporated sampling and post-stratification weights in all analyses to yield nationally representative estimates. 
Rai et al

\begin{tabular}{|c|c|c|c|c|}
\hline & \multicolumn{4}{|c|}{ Age Group } \\
\hline & \multicolumn{2}{|c|}{ Age $18-64$ y } & \multicolumn{2}{|c|}{ Age $\geq 65 y$} \\
\hline & $\mathrm{n}$ & Weighted \% & $\mathrm{n}$ & Weighted $\%$ \\
\hline \multicolumn{5}{|l|}{ Age, y } \\
\hline $18-44$ & 557 & 22.1 & - & - \\
\hline $45-49$ & 276 & 12.0 & - & - \\
\hline $50-54$ & 367 & 16.3 & - & - \\
\hline $55-59$ & 463 & 21.6 & - & - \\
\hline $60-64$ & 594 & 28.0 & - & - \\
\hline $65-69$ & - & - & 623 & 24.4 \\
\hline $70-74$ & - & - & 499 & 22.4 \\
\hline$\geq 75$ & - & - & 1,209 & 53.3 \\
\hline \multicolumn{5}{|l|}{ Sex } \\
\hline Female & 1,600 & 66.9 & 1,211 & 51.6 \\
\hline Male & 657 & 33.1 & 1,120 & 48.4 \\
\hline \multicolumn{5}{|l|}{ Race/Ethnicity } \\
\hline Non-Hispanic white & 1,749 & 88.2 & 1,888 & 91.3 \\
\hline Others/Missing & 508 & 11.8 & 443 & 8.7 \\
\hline \multicolumn{5}{|l|}{ Marital status } \\
\hline Currently married & 1,280 & 63.4 & 1,249 & 53.6 \\
\hline Others/Missing & 977 & 36.6 & 1,082 & 46.4 \\
\hline \multicolumn{5}{|l|}{ Education } \\
\hline Less than high school & 83 & 2.2 & 207 & 5.6 \\
\hline High school & 765 & 29.4 & 862 & 35.7 \\
\hline College & 1,075 & 53.6 & 902 & 42.8 \\
\hline Missing & 334 & 14.8 & 360 & 15.9 \\
\hline \multicolumn{5}{|l|}{ Income level ${ }^{a}$} \\
\hline Low & 543 & 17.3 & 474 & 13.7 \\
\hline Middle & 896 & 35.9 & 1,106 & 46.6 \\
\hline High & 818 & 46.8 & 751 & 39.7 \\
\hline \multicolumn{5}{|l|}{ Insurance coverage } \\
\hline $\begin{array}{l}\text { Age } 18-64 \text { y, any } \\
\text { private }\end{array}$ & 1,490 & 75.0 & - & - \\
\hline $\begin{array}{l}\text { Age } 18-64 \text { y, public } \\
\text { only }\end{array}$ & 545 & 16.5 & - & - \\
\hline Age $18-64$ y, uninsured & 222 & 8.5 & - & - \\
\hline $\begin{array}{l}\text { Age } \geq 65 y \text {, Medicare } \\
\text { only }\end{array}$ & - & - & 844 & 35.5 \\
\hline $\begin{array}{l}\text { Age } \geq 65 \text { y, Medicare } \\
\text { and private }\end{array}$ & - & - & 1,149 & 54.2 \\
\hline
\end{tabular}

\begin{tabular}{|c|c|c|c|c|}
\hline & \multicolumn{4}{|c|}{ Age Group } \\
\hline & \multicolumn{2}{|c|}{ Age $18-64$ y } & \multicolumn{2}{|c|}{ Age $\geq 65 y$} \\
\hline & $\mathrm{n}$ & Weighted \% & $\mathbf{n}$ & Weighted \% \\
\hline $\begin{array}{l}\text { Age } \geq 65 y \text {, Medicare } \\
\text { and other public }\end{array}$ & - & - & 338 & 10.3 \\
\hline \multicolumn{5}{|l|}{ Usual source of care } \\
\hline No/Missing & 256 & 10.6 & 121 & 4.8 \\
\hline Yes & 2,001 & 89.4 & 2,210 & 95.2 \\
\hline \multicolumn{5}{|l|}{ Smoking status } \\
\hline Smoker & 520 & 22.3 & 202 & 7.8 \\
\hline Nonsmoker/Missing & 1,737 & 77.7 & 2,129 & 92.2 \\
\hline \multicolumn{5}{|c|}{ Number of comorbidities ${ }^{b}$} \\
\hline 0 & 686 & 32.2 & 209 & 10.0 \\
\hline 1 & 644 & 29.7 & 530 & 22.9 \\
\hline Age $18-64 \mathrm{y}: \geq 2$ & 927 & 38.1 & - & - \\
\hline Age $\geq 65$ y: 2 & - & - & 693 & 29.8 \\
\hline Age $\geq 65$ y: 3 & - & - & 452 & 19.0 \\
\hline Age $\geq 65$ y: $\geq 4$ & - & - & 447 & 18.3 \\
\hline \multicolumn{5}{|c|}{ Active treatment within 2 years of survey } \\
\hline No & 1,388 & 58.6 & 1,215 & 48.5 \\
\hline Yes & 869 & 41.4 & 1,116 & 51.5 \\
\hline \multicolumn{5}{|c|}{ Tertiles of physician office visits in year 1} \\
\hline First (T1) & 952 & 39.9 & 871 & 34.2 \\
\hline Second (T2) & 611 & 28.3 & 752 & 32.9 \\
\hline Third (T3) & 694 & 31.8 & 708 & 32.9 \\
\hline \multicolumn{5}{|l|}{ Any ED visits in year 1} \\
\hline No & 1,733 & 78.4 & 1,806 & 77.8 \\
\hline Yes & 524 & 21.6 & 525 & 22.2 \\
\hline \multicolumn{5}{|c|}{ Any hospital admissions in year 1} \\
\hline No & 1,879 & 83.3 & 1,855 & 78.9 \\
\hline Yes & 378 & 16.8 & 476 & 21.1 \\
\hline \multicolumn{5}{|l|}{ Panel number } \\
\hline 13 & 363 & 16.1 & 319 & 16.1 \\
\hline 14 & 321 & 14.2 & 360 & 13.0 \\
\hline 15 & 277 & 12.3 & 294 & 12.5 \\
\hline 16 & 370 & 16.4 & 408 & 16.3 \\
\hline 17 & 330 & 14.6 & 347 & 15.4 \\
\hline 18 & 297 & 13.2 & 287 & 12.5 \\
\hline 19 & 299 & 13.2 & 316 & 14.2 \\
\hline
\end{tabular}

Abbreviation: ED, emergency department.

aDefined as family income of $<100 \%-124 \%$ (low), $125 \%-399 \%$ (middle), and $\geq 400 \%$ (high) of federal poverty line.

berived from the following 8 self-reported ailments: arthritis, asthma, cerebrovascular disease, coronary artery disease, diabetes mellitus, emphysema, hypertension, and myocardial infarction.

\section{Results}

We identified 4,588 cancer survivors, of which 2,257 were nonelderly (age 18-64 years) and 2,331 were elderly (age $\geq 65$ years). Respondents' demographic, healthcare access, and baseline health characteristics are listed in Table 1. The median age of the study sample was 54 years among the nonelderly cohort and 75 years among the elderly. Frequency distributions of cancer sites and specific comorbidities are displayed in supplemental eTables 1 and 2 (available with this article at JNCCN.org). As a comparison, eTable 2 also includes the frequency distribution of comorbidities among MEPS respondents without a cancer history from the corresponding panel-range.
Figure 1 shows the distribution of scores for specific questions and global satisfaction ratings.

Table 2 shows the results from multivariable logistic regression, with membership of the highest satisfaction tertile as the dependent variable. Among the nonelderly, the odds of membership of the highest satisfaction tertile were higher among older respondents (age 18-44 years: reference category [ref]; age 55-59 years: odds ratio [OR], 1.67; $P=.002$; age 60-64 years: $\mathrm{OR}, 1.56 ; P=.016)$. In the same age group, satisfaction ratings were negatively associated with number of comorbidities ( 0 comorbidities: ref; $\geq 2$ comorbidities: OR, $0.69 ; P=.015)$ and increasing tertiles of office visits in year 1 (tertile 1 [T1]: ref; tertile 2 [T2]: OR, 0.76; $P=.034$; tertile 3 [T3]: OR, 


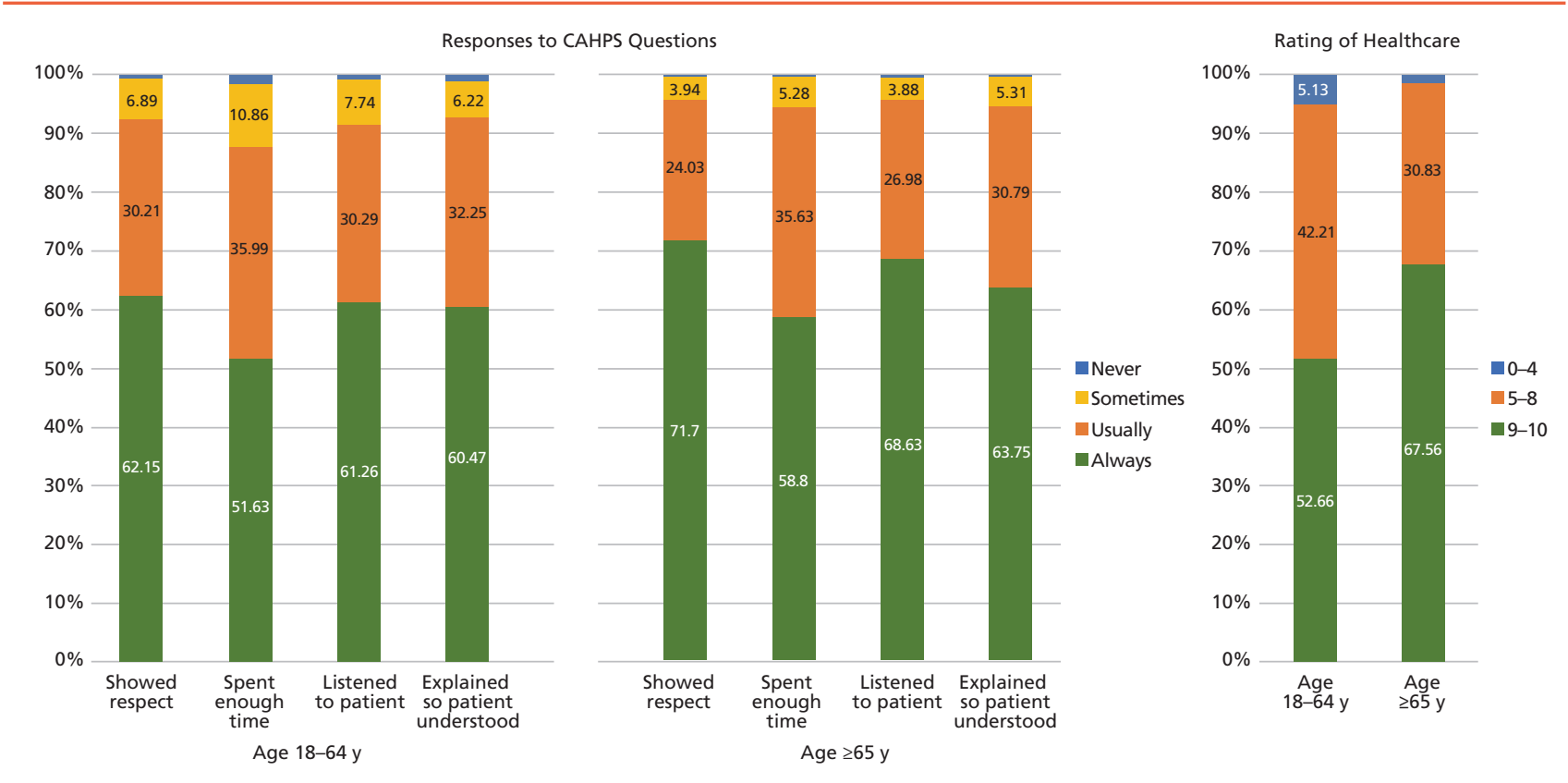

Figure 1. Distribution of responses to CAHPS questions and overall rating of healthcare among respondents with a history of cancer diagnosis. Abbreviation: CAHPS, Consumer Assessment of Healthcare Providers and Systems.

0.54; $P<.001)$. Among the elderly, satisfaction ratings were lower among respondents with $\geq 4$ comorbidities ( 0 comorbidities: ref; $\geq 4$ comorbidities: $O R$, $0.65 ; P=.044)$ and those with any ED visit in year 1 (no ED visits: ref; any ED visit: $\mathrm{OR}, 0.63 ; P=.002$ ).

Among the elderly, higher patient satisfaction in year 1 was associated with membership of the highest year 2 mental health tertile (satisfaction T1 [ref]: PM, 27.1\%; T2: PM, 35.5\%; P=.013; T3: PM, 37.0\%; $P=.005)$, and the highest year 2 general health tertile (T1 [ref]: PM, 30.3\%; T3: PM, 38.9\%; P=.007) (Table 3). Among the nonelderly, the relationship between satisfaction ratings and mental health was not consistent across satisfaction tertiles (T1 [ref]: PM, 29.7\%; T2: PM, 36.0\%; P=.036; T3: PM, 34.0\%; $P=.187)$. Highest year 1 satisfaction tertile was associated with fewer office visits among the nonelderly (T1 [ref]: PM, 7.42; T3: PM, 6.26; P=.038) and lower year 2 total healthcare expenditure among the elderly (T1 [ref]: PM, \$34,071; T3: PM, \$26,995; P=.049). Similarly, greater year 1 satisfaction was associated with lesser healthcare expenditure among the nonelderly and fewer year 2 office visits among the elderly, but these results were statistically insignificant.

\section{Discussion}

In this study, we used a large nationally representative survey with longitudinal data to explore satisfaction with healthcare provider communication among cancer survivors. Our primary findings were: (1) in both elderly and nonelderly cancer survivors, greater satisfaction with provider communication was associated with better baseline health status, as measured by fewer year 1 comorbidities, fewer office visits, or absence of ED visits; and (2) higher satisfaction in year 1 was associated with better health ratings, fewer office visits (nonelderly only), and lower total healthcare expenditure (elderly only) in year 2 .

The presence of multiple comorbidities may adversely influence satisfaction ratings through alternative pathways. Illness complexity is likely to affect a patient's perception of the care experience. ${ }^{28,29}$ Alternatively, variations by comorbidities also may reflect genuine differences in the quality of care received. Providers may find it challenging to convey a large volume of information to clinically complex patients, especially within the resource and time constraints of an outpatient visit. Multiple comorbidities also may lead to greater fragmentation of care, ${ }^{30,31}$ which may adversely affect satisfaction ratings. 
Rai et al

Table 2. Adjusted Associations Between Survivor Characteristics and Highest Satisfaction Tertile

\begin{tabular}{|c|c|c|c|c|c|c|}
\hline & \multicolumn{6}{|c|}{ Age Group } \\
\hline & \multicolumn{3}{|c|}{ Age $18-64$ y } & \multicolumn{3}{|c|}{ Age $\geq 65 y$} \\
\hline & OR & $95 \% \mathrm{Cl}$ & $P$ Value & OR & $95 \% \mathrm{Cl}$ & $P$ Value \\
\hline \multicolumn{7}{|l|}{ Age, y } \\
\hline $18-44$ & Ref & - & & - & - & \\
\hline $45-49$ & 1.18 & $0.82-1.70$ & .370 & - & - & \\
\hline $50-54$ & 1.42 & $0.95-2.13$ & .084 & - & - & \\
\hline $55-59$ & 1.67 & $1.21-2.30$ & .002 & - & - & \\
\hline $60-64$ & 1.56 & $1.09-2.25$ & .016 & - & - & \\
\hline $65-69$ & - & - & & Ref & - & \\
\hline $70-74$ & - & - & & 1.06 & $0.77-1.44$ & .733 \\
\hline$\geq 75$ & - & - & & 0.93 & $0.71-1.21$ & .575 \\
\hline \multicolumn{7}{|l|}{ Sex } \\
\hline Male & Ref & - & & Ref & - & \\
\hline Female & 1.20 & $0.95-1.51$ & .127 & 0.98 & $0.80-1.21$ & .884 \\
\hline \multicolumn{7}{|l|}{ Race/Ethnicity } \\
\hline Non-Hispanic white & Ref & - & & Ref & - & \\
\hline Others/Missing & 1.09 & $0.86-1.37$ & .484 & 0.90 & $0.69-1.17$ & .439 \\
\hline \multicolumn{7}{|l|}{ Marital status } \\
\hline Currently married & Ref & - & & Ref & - & \\
\hline Others/Missing & 0.87 & $0.68-1.10$ & .234 & 1.21 & $0.97-1.50$ & .090 \\
\hline \multicolumn{7}{|l|}{ Education } \\
\hline Less than high school & Ref & - & & Ref & - & \\
\hline High school & 0.82 & $0.42-1.60$ & .559 & 0.92 & $0.60-1.42$ & .717 \\
\hline College & 0.75 & $0.39-1.46$ & .401 & 0.93 & $0.60-1.44$ & .742 \\
\hline Missing & 0.96 & $0.08-11.3$ & .974 & 0.86 & $0.09-8.47$ & .895 \\
\hline \multicolumn{7}{|l|}{ Income level ${ }^{\mathrm{a}}$} \\
\hline Low & Ref & - & & Ref & - & \\
\hline Middle & 1.19 & $0.87-1.61$ & .279 & 1.19 & $0.89-1.60$ & .237 \\
\hline High & 1.21 & $0.83-1.77$ & .318 & 1.07 & $0.77-1.49$ & .696 \\
\hline \multicolumn{7}{|l|}{ Insurance coverage } \\
\hline Age $18-64 y$, any private & Ref & - & & - & - & \\
\hline Age $18-64$ y, public only & 0.81 & $0.61-1.09$ & .167 & - & - & \\
\hline Age $18-64$ y, uninsured & 0.66 & $0.42-1.02$ & .064 & - & - & \\
\hline Age $\geq 65 y$, Medicare only & - & - & & Ref & - & \\
\hline Age $\geq 65 y$, Medicare and private & - & - & & 1.00 & $0.80-1.27$ & .970 \\
\hline Age $\geq 65$ y, Medicare and other public & - & - & & 0.91 & $0.64-1.30$ & .590 \\
\hline \multicolumn{7}{|l|}{ Usual source of care } \\
\hline No/Missing & Ref & - & & Ref & - & \\
\hline Yes & 1.53 & $1.00-2.35$ & .050 & 1.55 & $0.94-2.56$ & .060 \\
\hline \multicolumn{7}{|l|}{ Smoking status } \\
\hline Smoker & Ref & - & & Ref & - & \\
\hline Nonsmoker/Missing & 1.21 & $0.90-1.61$ & .200 & 1.43 & $1.00-1.99$ & .050 \\
\hline \multicolumn{7}{|l|}{ Number of comorbidities ${ }^{b}$} \\
\hline 0 & Ref & - & & Ref & - & \\
\hline 1 & 0.83 & $0.62-1.10$ & .194 & 0.99 & $0.66-1.48$ & .968 \\
\hline Age $18-64$ y: $\geq 2$ & 0.69 & $0.51-0.93$ & .015 & - & - & \\
\hline Age $\geq 65$ y: 2 & & & & 0.78 & $0.53-1.16$ & .214 \\
\hline Age $\geq 65$ y: 3 & - & - & & 0.87 & $0.56-1.35$ & .526 \\
\hline Age $\geq 65 y: \geq 4$ & - & - & & 0.65 & $0.42-0.98$ & .044 \\
\hline \multicolumn{7}{|l|}{ Active treatment within 2 years of survey } \\
\hline No & Ref & - & & Ref & - & \\
\hline Yes & 1.05 & $0.84-1.31$ & .670 & 1.00 & $0.81-1.23$ & .997 \\
\hline Tertiles of physician office visits in year 1 & & & & & & \\
\hline First (T1) & Ref & - & & Ref & - & \\
\hline Second (T2) & 0.76 & $0.59-0.98$ & .034 & 0.97 & $0.75-1.26$ & .837 \\
\hline Third (T3) & 0.54 & $0.40-0.74$ & $<.001$ & 0.84 & $0.66-1.06$ & .139 \\
\hline Any ED visits in year 1 & & & & & & \\
\hline No & Ref & - & & Ref & - & \\
\hline Yes & 0.87 & $0.65-1.17$ & .353 & 0.63 & $0.48-0.84$ & .002 \\
\hline Any hospital admissions in year 1 & & & & & & \\
\hline No & Ref & - & & Ref & - & \\
\hline Yes & 1.18 & $0.85-1.64$ & .322 & 1.29 & $0.96-1.72$ & .088 \\
\hline
\end{tabular}

Note: Panel numbers controlled for but not reported.

Abbreviations: $E D$, emergency department; OR, odds ratio.

a Defined as family income of $<100 \%-124 \%$ (low), $125 \%-399 \%$ (middle), and $\geq 400 \%$ (high) of federal poverty line

berived from the following 8 self-reported ailments: arthritis, asthma, cerebrovascular disease, coronary artery disease, diabetes mellitus, emphysema,

hypertension, and myocardial infarction. 
Although the association between better baseline health and greater satisfaction with provider communication has been reported earlier, ${ }^{14}$ a similar association among cancer survivors in the present study deserves closer consideration. Not only are comorbid illnesses more common among cancer survivors than the general population ${ }^{32}$ but also a diagnosis of cancer may augment all the mentioned pathways. Thus, our results highlight the importance of accounting for patient mix in payment formulas to the extent that providers who care for complex cancer survivors are adequately compensated. At the same time, provider teams need to be equipped with systems and training to coordinate survivorship care. ${ }^{9}$ It has been reported that, with increasing subspecial- izations in cancer treatment, providers often lack the skills to manage the wide array of other ailments that may be present in this population..$^{33}$ Therefore, it is incumbent on physician training programs to facilitate the development of skills required to care for complex survivors, including managing comorbidities, identifying and addressing special needs of those with multiple ailments, and coordinating care.

Our results are consistent with those of previous studies indicating associations among patient experience, clinical effectiveness, and patient safety. For instance, a meta-analysis showed that better quality of patient-provider communication was positively associated with adherence to treatment in an overwhelming majority of studies. ${ }^{34}$ Better patient expe-

\section{Table 3. Adjusted Relationships Between Year 1 Satisfaction Tertiles and Year 2 Self-Rated Health,} Service Use, and Expenditures

\begin{tabular}{|c|c|c|c|}
\hline \multirow[b]{3}{*}{ Variable } & \multicolumn{3}{|c|}{ Patient Satisfaction Tertile } \\
\hline & 1 (Least Satisfied) & 2 & 3 (Most Satisfied) \\
\hline & & Age $18-64$ y & \\
\hline \multicolumn{4}{|l|}{ Excellent/Very good general health } \\
\hline Unadjusted proportion (\%) & 29.6 & 38.2 & 49.2 \\
\hline $\mathrm{PM}(95 \% \mathrm{Cl})$ & $38.0(33.9-42.2)$ & $38.1(34.8-41.4)$ & $41.1(37.2-45.0)$ \\
\hline$P$ value & Ref & .982 & .306 \\
\hline \multicolumn{4}{|l|}{ Highest quartile of mental health } \\
\hline Unadjusted proportion (\%) & 23.5 & 35.5 & 41.1 \\
\hline $\mathrm{PM}(95 \% \mathrm{Cl})$ & $29.7(25.3-34.1)$ & $36.0(31.3-40.7)$ & $34.0(29.5-38.4)$ \\
\hline$P$ value & Ref & .036 & .187 \\
\hline \multicolumn{4}{|l|}{ Highest quartile of physical health } \\
\hline Unadjusted proportion (\%) & 26.1 & 33.5 & 40.2 \\
\hline PM (\%) & $32.5(27.9-37.1)$ & $32.4(28.5-36.3)$ & $35.4(31.6-39.1)$ \\
\hline$P$ value & Ref & .952 & .355 \\
\hline \multicolumn{4}{|l|}{ Total ED visits } \\
\hline Unadjusted mean & 0.39 & 0.26 & 0.26 \\
\hline $\mathrm{PM}(95 \% \mathrm{Cl})$ & $0.29(0.24-0.35)$ & $0.32(0.23-0.39)$ & $0.34(0.25-0.42)$ \\
\hline$P$ value & Ref & .853 & .4 \\
\hline \multicolumn{4}{|l|}{ Total hospital admissions } \\
\hline Unadjusted mean & 0.22 & 0.19 & 0.15 \\
\hline $\mathrm{PM}(95 \% \mathrm{Cl})$ & $0.18(0.14-0.22)$ & $0.21(0.13-0.28)$ & $0.19(0.13-0.26)$ \\
\hline$P$ value & Ref & .449 & .87 \\
\hline \multicolumn{4}{|l|}{ Total physician office visits } \\
\hline Unadjusted mean & 7.96 & 6.96 & 5.85 \\
\hline $\mathrm{PM}(95 \% \mathrm{Cl})$ & $7.42(6.78-8.06)$ & $6.60(5.98-7.22)$ & $6.26(5.47-7.05)$ \\
\hline$P$ value & Ref & .211 & .038 \\
\hline \multicolumn{4}{|l|}{ Total healthcare expenditure } \\
\hline Unadjusted mean & $\$ 21,661$ & $\$ 26,465$ & $\$ 18,059$ \\
\hline $\mathrm{PM}(95 \% \mathrm{Cl})$ & $\$ 22,143(\$ 17,024-\$ 27,262)$ & $\$ 26,706(\$ 18,279-\$ 35,133)$ & $\$ 22,547(\$ 15,785-\$ 29,309)$ \\
\hline$P$ value & Ref & .189 & .716 \\
\hline \multicolumn{4}{|l|}{ Total drug expenditure } \\
\hline Unadjusted mean & $\$ 2,877$ & $\$ 2,921$ & $\$ 2,560$ \\
\hline $\mathrm{PM}(95 \% \mathrm{Cl})$ & $\$ 2,927(\$ 2,479-\$ 3,375)$ & $\$ 2,822(\$ 2,315-\$ 3,329)$ & $\$ 2,940(\$ 2,282-\$ 3,598)$ \\
\hline$P$ value & Ref & .704 & .87 \\
\hline \multicolumn{4}{|l|}{ Total out-of-pocket expenditure } \\
\hline Unadjusted mean & $\$ 1,403$ & $\$ 1,428$ & $\$ 1,072$ \\
\hline $\mathrm{PM}(95 \% \mathrm{Cl})$ & $\$ 1,409(\$ 1,159-\$ 1,659)$ & $\$ 1,292(\$ 1,060-\$ 1,526)$ & $\$ 1,150(\$ 947-\$ 1,355)$ \\
\hline$P$ value & Ref & .78 & .089 \\
\hline
\end{tabular}


Rai et al

\begin{tabular}{|c|c|c|c|}
\hline \multirow[b]{3}{*}{ Variable } & \multicolumn{3}{|c|}{ Patient Satisfaction Tertile } \\
\hline & 1 (Least Satisfied) & 2 & 3 (Most Satisfied) \\
\hline & & Age $\geq 65 \mathrm{y}$ & \\
\hline \multicolumn{4}{|l|}{ Excellent/Very good general health } \\
\hline Unadjusted proportion (\%) & 23.6 & 31.8 & 45.8 \\
\hline PM $(95 \% \mathrm{Cl})$ & $30.3(26.0-34.6)$ & $32.2(28.9-35.5)$ & $38.9(35.1-42.7)$ \\
\hline$P$ value & Ref & .466 & .007 \\
\hline \multicolumn{4}{|l|}{ Highest quartile of mental health } \\
\hline Unadjusted proportion (\%) & 22.9 & 34.8 & 41.7 \\
\hline $\mathrm{PM}(95 \% \mathrm{Cl})$ & $27.1(22.1-32.1)$ & $35.5(31.5-39.5)$ & $37.0(32.7-41.4)$ \\
\hline$P$ value & Ref & .013 & .005 \\
\hline \multicolumn{4}{|l|}{ Highest quartile of physical health } \\
\hline Unadjusted proportion (\%) & 25.1 & 32.1 & 42.5 \\
\hline PM (\%) & $32.9(28.9-36.8)$ & $31.4(27.4-35.3)$ & $35.8(32.3-39.3)$ \\
\hline$P$ value & Ref & .586 & .314 \\
\hline \multicolumn{4}{|l|}{ Total ED visits } \\
\hline Unadjusted mean & 0.40 & 0.29 & 0.31 \\
\hline $\mathrm{PM}(95 \% \mathrm{Cl})$ & $0.37(0.32-0.44)$ & $0.28(0.21-0.34)$ & $0.30(0.24-0.36)$ \\
\hline$P$ value & Ref & .070 & .238 \\
\hline \multicolumn{4}{|l|}{ Total hospital admissions } \\
\hline Unadjusted mean & 0.33 & 0.29 & 0.28 \\
\hline PM $(95 \% \mathrm{Cl})$ & $0.30(0.25-0.35)$ & $0.30(0.23-0.37)$ & $0.31(0.24-0.37)$ \\
\hline$P$ value & Ref & .990 & .744 \\
\hline \multicolumn{4}{|l|}{ Total physician office visits } \\
\hline Unadjusted mean & 10.03 & 9.43 & 9.09 \\
\hline $\mathrm{PM}(95 \% \mathrm{Cl})$ & $9.55(8.90-10.19)$ & $9.68(8.71-10.64)$ & $9.32(8.24-10.40)$ \\
\hline$P$ value & Ref & .65 & .619 \\
\hline \multicolumn{4}{|l|}{ Total healthcare expenditure } \\
\hline Unadjusted mean & $\$ 33,558$ & $\$ 27,341$ & $\$ 29,591$ \\
\hline PM $(95 \% \mathrm{Cl})$ & $\$ 34,071(\$ 29,011-\$ 39,131)$ & $\$ 28,230(\$ 22,907-\$ 33,553)$ & $\$ 26,995(\$ 22,568-\$ 31,422)$ \\
\hline$P$ value & Ref & .301 & .049 \\
\hline \multicolumn{4}{|l|}{ Total drug expenditure } \\
\hline Unadjusted mean & $\$ 2,612$ & $\$ 2,620$ & $\$ 2,577$ \\
\hline $\mathrm{PM}(95 \% \mathrm{Cl})$ & $\$ 2,572(\$ 2,307-\$ 2,837)$ & $\$ 2,775(\$ 2,459-\$ 3,092)$ & $\$ 2,851(\$ 2,467-\$ 3,236)$ \\
\hline$P$ value & Ref & .445 & 261 \\
\hline \multicolumn{4}{|l|}{ Total out-of-pocket expenditure } \\
\hline Unadjusted mean & $\$ 1,579$ & $\$ 1,265$ & $\$ 1,290$ \\
\hline PM $(95 \% \mathrm{Cl})$ & $\$ 1,515(\$ 1,281-\$ 1,749)$ & $\$ 1,242(\$ 1,059-\$ 1,425)$ & $\$ 1,229(\$ 1,080-1,378)$ \\
\hline$P$ value & Ref & 132 & .080 \\
\hline
\end{tabular}

All models controlled for age, sex, race, marital status, education, poverty, insurance, usual source of provider, panel number, comorbidity count, smoking status, year $1 \mathrm{SF}$ Physical and Mental Component Summary scores, year 1 self-rated general health, year 1 ED visits (any vs none), year 1 hospital admissions (any vs none), year 1 physician office visits, year 1 total healthcare expenditures, year 1 drug expenditures, and year 1 out-of-pocket spending.

Abbreviations: ED, emergency department; PM, predictive margin; SF, short form.

rience also has been found to be positively associated with medication compliance ${ }^{35-37}$ and performance on patient safety indicators. ${ }^{38}$ Recently, enhancing communication between patients with cancer and their healthcare team through electronic patientreported outcomes systems was shown to improve overall survival..$^{39,40}$

Effective patient-provider communication is beneficial for patients, clinicians, and hospitals alike. However, given the scarcity of time for such communication, concerns have been raised that higher satisfaction ratings may align with greater volume of care and not necessarily with high-value care. ${ }^{41,42}$ A previous analysis of the general population using the MEPS data found that higher satisfaction rat- ings were associated with greater service use, including inpatient visits and drug expenditures. ${ }^{14}$ Older studies also have linked patient satisfaction with the extent of fulfilment of patient requests. ${ }^{43,44}$ To the contrary, we found that greater satisfaction was associated with fewer physician office visits among younger respondents and lower total healthcare expenditure among the elderly. These departures from earlier findings may stem from the greater complexity of cancer survivorship care compared with the care delivered to the general population. Cancer survivors often require periodic visits to health professionals from multiple disciplines. Although vital, the frequency of these visits also can compound the distress caused by the diagnosis of cancer, its treatment, 
and follow-up. ${ }^{45,46}$ In this context, effective provider communication can streamline survivorship care and improve health outcomes by alleviating anxiety, boosting mutual trust, and enhancing self-care efficacy and adherence. ${ }^{10}$ Overall, our results suggest that addressing survivors' concerns also align well with efficient use of healthcare services. That said, more research is needed to better understand the complex relationship between survivors' satisfaction with provider communication and service use.

Our findings should be interpreted in the light of several limitations. First, our study sample comprises cancer survivors in all phases of the cancer care continuum, including recently diagnosed and long-term survivors. The satisfaction scores that form the foundation of our analyses also are not reflective specifically of the quality of cancer care received. Restricting the analysis to those with a recent diagnosis of cancer would have allowed us to better focus on satisfaction with provider communication for cancerdirected care. However, cancer survivors identified in household surveys such as the MEPS generally are long-term survivors. Furthermore, beginning in 2013, variables indicating time since cancer diagnosis were removed from the MEPS for confidentiality concerns. Thus, the numbers of recently diagnosed survivors are insufficient for separate analyses.

Second, in our examination of the relationship between patient satisfaction and outcomes, we could not control for some potentially important confounders that were not available in the data, including disease stage at diagnosis, all specific cancer treatments since diagnosis, time since last cancerdirected treatment (for those not treated within 2 years of survey), provider characteristics, and financial burden of cancer care. Information on cancer sites also could not be incorporated into the analyses due to insufficient numbers. Future studies should address these limitations using larger, more-detailed, cancer-focused data to evaluate care experiences that are unique to cancer survivors. Potential databases include the Consumer Assessment of Healthcare Providers and Systems (CAHPS) Cancer Care Survey and the SEER-CAHPS linked data. ${ }^{47-50}$ The former was designed to measure respondents' experiences while they receive cancer-directed treatments, whereas the SEER-CAHPS linkage provides data on Medicare beneficiaries' experiences at various phases of cancer care.

The above limitations notwithstanding, to our knowledge, this is the first nationally representative study of the drivers and outcomes of cancer survivors' satisfaction with provider communication. We identified important determinants of satisfaction with provider communication among cancer survivors, including comorbidities and baseline service use. Our analyses adjusted for a comprehensive list of factors that may affect satisfaction with provider communication and estimated the short-term outcomes of satisfaction by taking advantage of the panel design of the MEPS.

\section{Conclusions}

The ongoing improvement in cancer survival has resulted in a population of survivors with many unique medical and psychosocial needs. Our results highlight the need for individualized communication strategies in cancer survivorship care. Notably, our results suggest that improving cancer survivors' satisfaction with provider communication would lead to better health outcomes in an efficient manner. Great interest is being shown in how to measure systematically and improve provider communication in cancer survivorship care. To those ends, our findings will motivate future inquiries into effective provider communication along the cancer care continuum, preferably using novel, cancer-based data sources, including the CAHPS Cancer Care Survey and the SEER-CAHPS linked data.

\section{References}

1. Institute of Medicine. Crossing the Quality Chasm: A New Health System for the 21st Century. Washington, DC: National Academies Press; 2001.

2. Total Performance Score Information. Medicare.gov. Available at: https:// www.medicare.gov/hospitalcompare/data/total-performance-scores.html. Accessed July 1, 2017.

3. Patient-Centered Outcomes Research Institute. Clinical Effectiveness and Decision Science. Communication and Dissemination Research. Available at: https://www.pcori.org/about-us/our-programs/clinical-effectivenessand-decision-science. Accessed April 1, 2017.

4. Selby J. Enhancing Communication to Advance Research and Practice is Among PCORI's Key Priorities. Health Affairs Blog. November 5, 2012. Available at: http://healthaffairs.org/blog/2012/11/05/enhancingcommunication-to-advance-research-and-practice-is-among-pcoris-keypriorities/. Accessed April 1, 2017.

5. Baile WF, Aaron J. Patient-physician communication in oncology: past, present, and future. Curr Opin Oncol 2005;17:331-335.

6. Beach WA, Dozier DM. Fears, uncertainties, and hopes: patient-initiated actions and doctors' responses during oncology interviews. J Health Commun 2015;20:1243-1254. 
7. Fallowfield L, Jenkins V. Communicating sad, bad, and difficult news in medicine. Lancet 2004;363:312-319.

8. Simard S, Thewes B, Humphris G, et al. Fear of cancer recurrence in adult cancer survivors: a systematic review of quantitative studies. J Cancer Surviv 2013;7:300-322.

9. Institute of Medicine and National Research Council. From Cancer Patient to Cancer Survivor: Lost in Transition. Washington, DC: The National Academies Press; 2006.

10. Epstein RM, Street RL Jr. Patient-centered communication in cancer care: promoting healing and reducing suffering. Bethesda, MD: National Cancer Institute; 2007. NIH Publication No. 07-6225.

11. Arora NK. Can you hear me now? Importance of assessing patients' cancer care experiences. J Oncol Pract 2017;13:515-518.

12. Mazor KM, Street RL, Sue VM, et al. Assessing patients' experiences with communication across the cancer care continuum. Patient Educ Couns 2016;99:1343-1348.

13. Street RL, Mazor KM, Arora NK. Assessing patient-centered communication in cancer care: measures for surveillance of communication outcomes. J Oncol Pract 2016;12:1198-1202.

14. Fenton JJ, Jerant AF, Bertakis KD, Franks P. The cost of satisfaction: a national study of patient satisfaction, health care utilization, expenditures, and mortality. Arch Intern Med 2012;172:405-411.

15. Cohen JW, Cohen SB, Banthin JS. The Medical Expenditure Panel Survey: a national information resource to support healthcare cost research and inform policy and practice. Med Care 2009;47(7 Suppl 1):S44-50.

16. National Cancer Institute. Office of Cancer Survivorship. Survivorship Definitions. Available at: https://cancercontrol.cancer.gov/ocs/statistics/ definitions.html. Accessed February 1, 2018.

17. Hargraves JL, Hays RD, Cleary PD. Psychometric properties of the Consumer Assessment of Health Plans Study (CAHPS) 2.0 adult core survey. Health Serv Res 2003;38:1509-1527.

18. De Vaus D. Surveys in Social Research. London, England: Routledge; 2013.

19. Ware J Jr, Kosinski M, Keller SD. A 12-item Short-Form Health Survey: construction of scales and preliminary tests of reliability and validity. Med Care 1996;34:220-233.

20. Zheng Z, Yabroff KR, Guy GP Jr, et al. Annual medical expenditure and productivity loss among colorectal, female breast, and prostate cancer survivors in the United States. J Natl Cancer Inst 2016;108:djv382.

21. Anhang Price R, Elliott MN, Cleary PD, et al. Should health care providers be accountable for patients' care experiences? J Gen Intern Med 2015;30:253-256.

22. Anhang Price R, Elliott MN, Zaslavsky AM, et al. Examining the role of patient experience surveys in measuring health care quality. Med Care Res Rev 2014;71:522-554.

23. Chawla N, Blanch-Hartigan D, Virgo KS, et al. Quality of patient-provider communication among cancer survivors: findings from a nationally representative sample. J Oncol Pract 2016;12:e964-973.

24. Elliott MN, Lehrman WG, Goldstein EH, et al. Hospital survey shows improvements in patient experience. Health Aff (Millwood) 2010;29:2061-2067.

25. Elliott MN, Zaslavsky AM, Goldstein E, et al. Effects of survey mode, patient mix, and nonresponse on CAHPS hospital survey scores. Health Serv Res 2009;44:501-518.

26. Palmer NR, Kent EE, Forsythe LP, et al. Racial and ethnic disparities in patient-provider communication, quality-of-care ratings, and patient activation among long-term cancer survivors. J Clin Oncol 2014;32:40874094 .

27. Graubard BI, Korn EL. Predictive margins with survey data. Biometrics 1999;55:652-659.

28. Fortin M, Bravo G, Hudon C, et al. Prevalence of multimorbidity among adults seen in family practice. Ann Fam Med 2005;3:223-228.
29. Wolff JL, Starfield B, Anderson G. Prevalence, expenditures, and complications of multiple chronic conditions in the elderly. Arch Intern Med 2002;162:2269-2276.

30. US Department of Health and Human Services. Multiple Chronic Conditions-A Strategic Framework: Optimum Health and Quality of Life for Individuals with Multiple Chronic Conditions. Washington, DC: US Department of Health and Human Services; 2010.

31. Walsh J, Harrison JD, Young JM, et al. What are the current barriers to effective cancer care coordination? A qualitative study. BMC Health Serv Res 2010;10:132.

32. Edwards BK, Noone AM, Mariotto AB, et al. Annual Report to the Nation on the status of cancer, 1975-2010, featuring prevalence of comorbidity and impact on survival among persons with lung, colorectal, breast, or prostate cancer. Cancer 2014;120:1290-1314.

33. Institute of Medicine. Delivering High-Quality Cancer Care: Charting a New Course for a System in Crisis. Washington, DC: The National Academies Press; 2013.

34. Zolnierek KB, Dimatteo MR. Physician communication and patient adherence to treatment: a meta-analysis. Med Care 2009;47:826-834.

35. Heisler M, Bouknight RR, Hayward RA, et al. The relative importance of physician communication, participatory decision making, and patient understanding in diabetes self-management. J Gen Intern Med 2002;17:243-252.

36. Kahn KL, Schneider EC, Malin JL, et al. Patient centered experiences in breast cancer: predicting long-term adherence to tamoxifen use. Med Care 2007;45:431-439.

37. Schneider EC, Zaslavsky AM, Landon BE, et al. National quality monitoring of Medicare health plans: the relationship between enrollees' reports and the quality of clinical care. Med Care 2001;39:1313-1325.

38. Isaac T, Zaslavsky AM, Cleary PD, Landon BE. The relationship between patients' perception of care and measures of hospital quality and safety. Health Serv Res 2010;45:1024-1040.

39. Basch E, Deal AM, Dueck AC, et al. Overall survival results of a trial assessing patient-reported outcomes for symptom monitoring during routine cancer treatment. JAMA 2017;318:197-198.

40. Smith AB, Basch E. Role of patient-reported outcomes in postsurgical monitoring in oncology. J Oncol Pract 2017;13:535-538

41. Jerant A, Fenton JJ, Kravitz RL, et al. Association of clinician denial of patient requests with patient satisfaction. JAMA Intern Med 2018;178:8591.

42. Tai-Seale M, McGuire TG, Zhang W. Time allocation in primary care office visits. Health Serv Res 2007;42:1871-1894.

43. Kravitz RL, Bell RA, Azari R, et al. Request fulfillment in office practice: antecedents and relationship to outcomes. Med Care 2002;40:38-51.

44. Rao JK, Weinberger M, Kroenke K. Visit-specific expectations and patientcentered outcomes: a literature review. Arch Fam Med 2000;9:1148-1155.

45. Oeffinger KC, McCabe MS. Models for delivering survivorship care. J Clin Oncol 2006;24:5117-5124.

46. Shapiro CL, Jacobsen PB, Henderson T, et al. ReCAP: ASCO core curriculum for cancer survivorship education. J Oncol Pract 2016;12:145, e108-117.

47. CAHPS Cancer Care Survey. Agency for Healthcare Research and Quality website. Available at: http://www.ahrq.gov/cahps/surveys-guidance/cancer/ index.html. Updated September 2017. Accessed April 1, 2017.

48. Chawla N, Urato M, Ambs A, et al. Unveiling SEER-CAHPS(R): a new data resource for quality of care research. J Gen Intern Med 2015;30:641650 .

49. Halpern MT, Urato MP, Lines LM, et al. Healthcare experience among older cancer survivors: analysis of the SEER-CAHPS dataset. J Geriatr Oncol 2018;9:194-203.

50. National Cancer Institute. SEER-CAHPS Linked Data Resource. Available at: https://healthcaredelivery.cancer.gov/seer-cahps/. Accessed April 1, 2017. 